\title{
Portal Hypertension and Fever Secondary to Granulomatous Hepatitis by Tuberculosis
}

\author{
Orivaldo Alves Barbosa ${ }^{\mathrm{a}, \mathrm{b}}$, Manoel Pedro Guedes Guimaraes ${ }^{\mathrm{a}}$, Andre Luis Coutinho de Araujo Macedo ${ }^{\mathrm{a}}$, \\ Jose Walter Correia ${ }^{a}$, Priscila Dourado Evangelista ${ }^{\text {a }}$, Barbara Irma Galdino Alves ${ }^{\mathrm{a}}$, \\ Cleto Dantas Nogueira ${ }^{a}$
}

\begin{abstract}
Tuberculosis (TB) is a highly prevalent disease in our country, eventually, most with atypical clinical presentations. We report a case of a young patient with prolonged fever and portal hypertension with clinical and histological diagnosis of granulomatous hepatitis, TB improved after treatment with anti-TB regimen. Then we have a brief literature review on the topic.
\end{abstract}

Keywords: Granulomatous hepatitis; Hepatic tuberculosis; Tuberculosis

\section{Introduction}

Tuberculosis (TB) is a chronic infectious disease caused by bacteria belonging to the Mycobacterium tuberculosis complex. It is considered one of the oldest infectious diseases of mankind. In Brazil, 70,047 new cases were reported in 2012 in the Notifiable Diseases Information System (Sinan), which is equivalent to the incidence of $36.1 / 100,000$ population [1].

TB most commonly affects the lungs (pulmonary TB). The main forms of extrapulmonary TB are pleural, peritoneal, pericardial, lymphatic, laryngeal, genitourinary, adrenal, bone, meningeal, intestinal, ophthalmic and skin. The hepatic granuloma TB occurs in about $20 \%$ of TB patients and up to $90 \%$ of them have a military form. It is common in this context. The isolated presentation of hepatic granulomas without lung disease, however, is less frequent and the presence of portal hypertension syndrome is considered a rare presentation [2-4].

In this paper, we present the case report of a male patient, 38 years old, with nonspecific clinical and laboratory findings, portal hypertension and histopathology analysis of liver

Manuscript accepted for publication June 03, 2015

${ }^{a}$ Medicine Unichristhus; Internal Medicine Service, Hospital Cesar Cals, Avenida do Imperador, 545, Centro, Fortaleza, Ceara, Brazil

${ }^{b}$ Corresponding Author: Orivaldo Alves Barbosa, Internal Medicine Service, Hospital Cesar Cals, Avenida do Imperador, 545, Centro, Fortaleza, Ceara, Brazil. Email: orivaldo.alves.barbosa@gmail.com

doi: http://dx.doi.org/10.14740/jmc2199w biopsies and spleen showing granulomas with caseous necrosis, suggestive of TB. We also present the literature review of granulomatous hepatitis, its causes and its relationship with portal hypertension.

\section{Case Report}

According to Resolution 196/96 of the National Health Council, the research did not present any risk to and assured no conflict of interest between the researcher and the subject of the study. Patient, 38 , previously healthy, developed fever $\left(39^{\circ} \mathrm{C}\right)$ and headache in April 2013 associated with appetite loss and postprandial fullness. After a month of onset of symptoms, fever became daily, preserving those traits accompanied by malaise and increased headache.

After a series of referrals, the patient was admitted to our institution with daily fever, about four episodes a day, without specific time of presentation, profuse night sweats and pale skin. He reported weight loss of approximately $7 \mathrm{~kg}$ in 3 months. Physical examination revealed significant hepatosplenomegaly with bicytopenia (anemia and leukopenia) to laboratory examination.

After admission, diagnostic investigation was performed (Table 1). An increase of portal and splenic vein caliber was found in abdominal tomography (Fig. 1) and Doppler portal.

We hypothesized lymphoproliferative disease, infectious mononucleosis, typhoid fever, schistosomiasis, Q fever, tuberculosis and leishmaniasis, from the clinical and epidemiological data. However, with the persistence of diagnostic uncertainty, the Medical Clinic Service opted for indication of liver biopsy and splenectomy, given the strong possibility of lymphoma and the therapeutic potential of surgery in these situations. The surgical procedure was performed on August 1, 2013 through swordtail-umbilical midline incision, performing removal of the spleen and liver portion to be sent for biopsy. The spleen biopsy (Fig. 2), liver (Fig. 3) and splenic hilum showed chronic granulomatous inflammation with central caseous necrosis and moderate lymphocytic infiltrate around without evidence of malignancy, with research for AFB and negative fungi. Based on this result, the hypothesis of granulomatous hepatitis of tuberculous etiology was discussed, and therapy with RIPE was started, with good response to treatment, general improvement, greater spacing and subsequent 
Table 1. Tests Performed in the Hospital

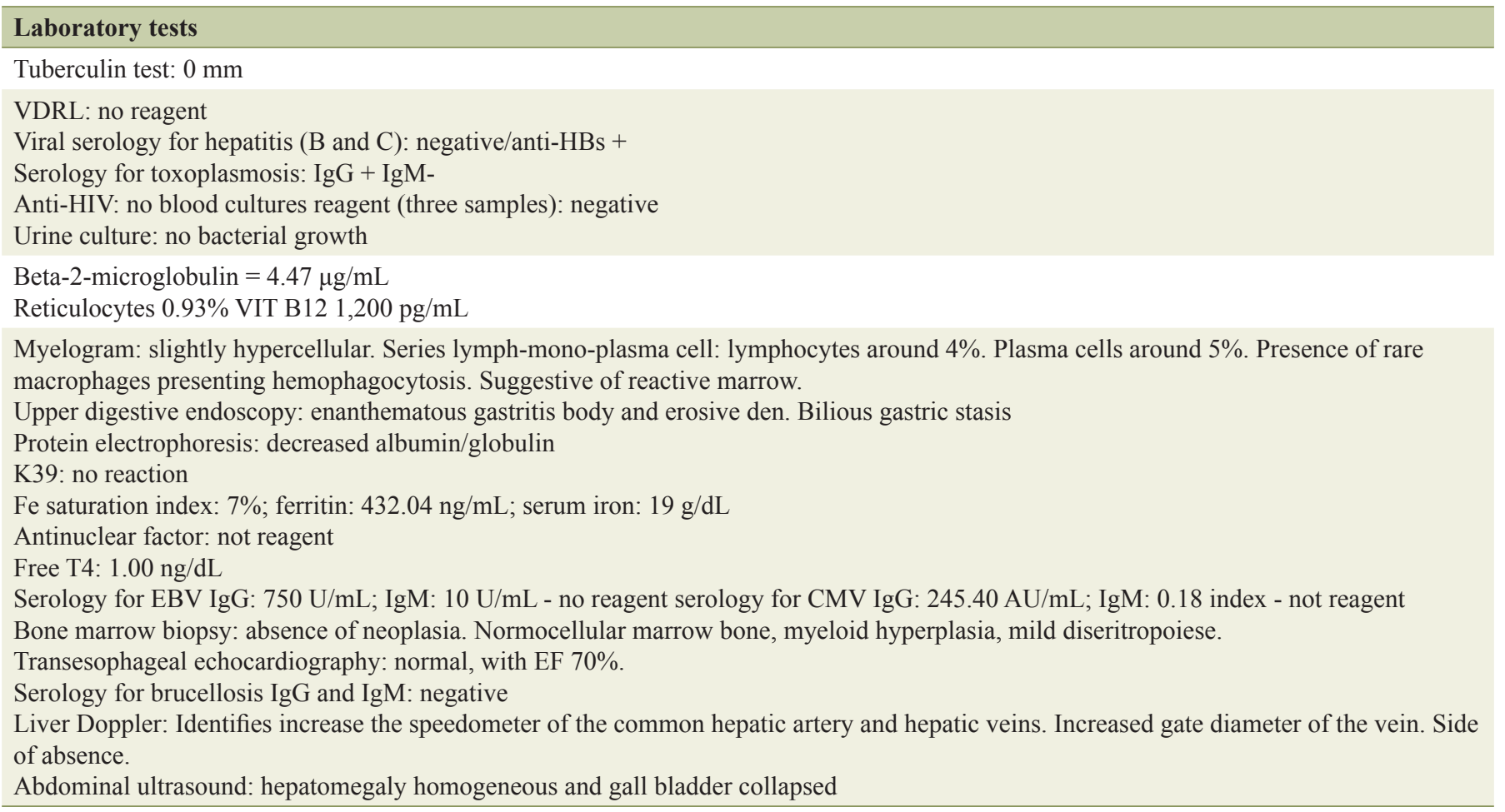

resolution of febrile episodes, weight gain and return to work activities.

\section{Discussion}

The presence of hepatic granulomas can be secondary to many diseases and is often a diagnostic clue to systemic conditions, and therapeutic and prognostic implications $[5,6]$.

The diagnosis of these pathological conditions requires

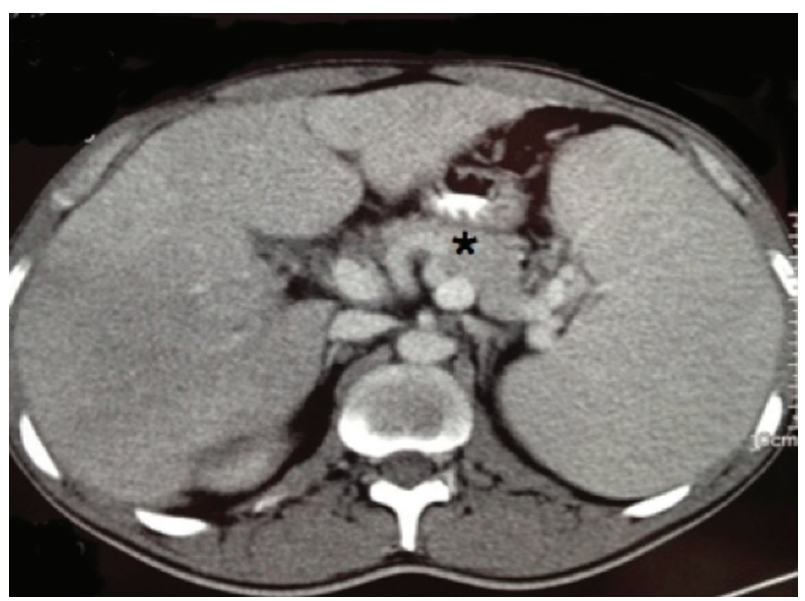

Figure 1. Abdominal tomography showing hepatosplenomegaly with heterogeneity of hepatic parenchyma and increased portal vein caliber and splenic (asterisk). the location and the type of granuloma which may aid in the differential diagnosis. Four major types can be identified: caseous granuloma (presence of central necrosis), noncaseating (without central necrosis) granuloma, lipogranulomas (core lipid containing vacuoles) and granulomas fibrinoanelares (central vacuoles containing fibrin deposit) [7].

Portal hypertension in this context is uncommon and is caused by the presence of multiple granulomas in portal region, secondary fibrosis inflammatory reaction, portal hypertension due to increased blood flow in cases of splenic involvement and, more rarely, thrombosis secondary to the prothrombotic state of portal vessels.

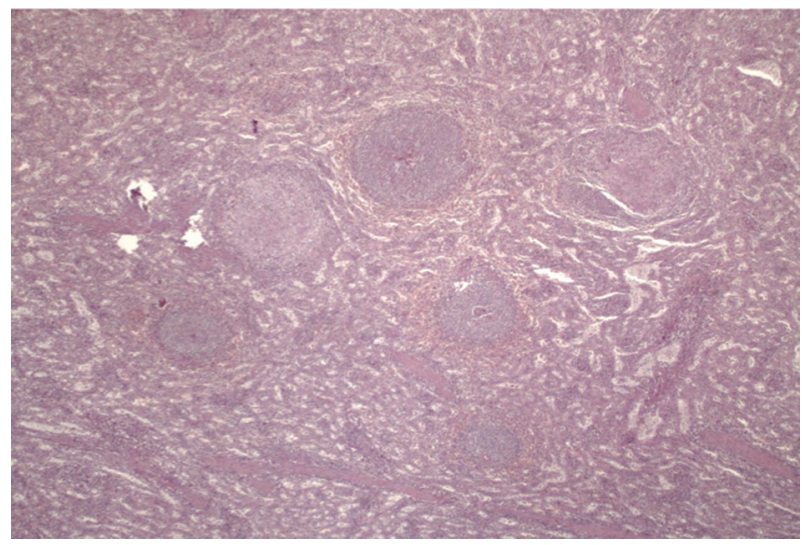

Figure 2. Splenic imaging with granulomas (rounded areas of lighter shade) at 16:19 hours. On average figure line, we observed lymphoid follicles. 


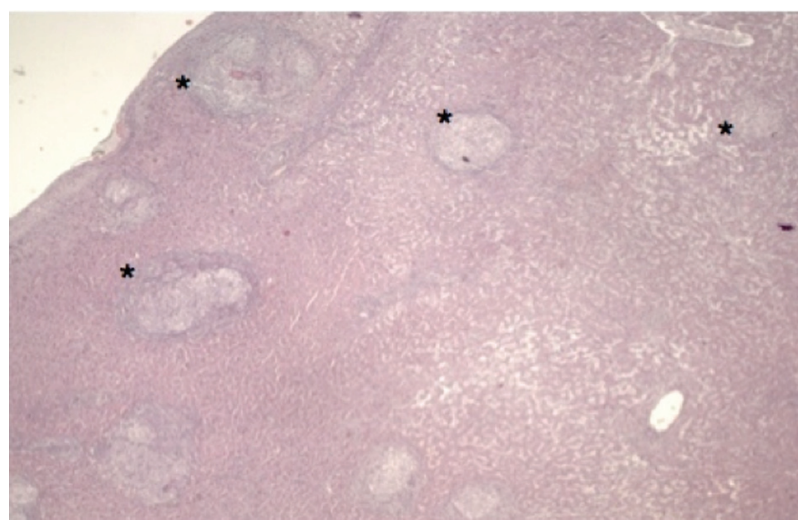

Figure 3. Image with diffuse hepatic granulomas with central necrosis (asterisks).

The main causes of granulomatous hepatitis in the developed world are autoimmune diseases, especially sarcoidosis, vasculitis, and primary biliary cirrhosis [5]. In developing countries, infectious causes dominate, led by TB, Q fever, brucellosis, Yersinia, Lyme disease, leprosy, mieloidose, and deep mycoses. In our case, the presence of granulomas caseating strongly suggests diseases such as TB, brucellosis and, rarely, Hodgkin's lymphoma. Direct analysis of bacilli was negative, but it presents a sensitivity of around $50 \%$. Together with systemic findings and the favorable therapeutic response, the most likely diagnosis is the liver TB.

\section{Conclusion}

Portal hypertension in the context of granulomatous hepatitis is rare; however, given the high prevalence of TB in Brazil, it should be considered in the differential diagnosis, especially if there are systemic symptoms compatible with miliary TB, such as prolonged fever, sweating, weight loss and increased GGT.

\section{Acknowledgement}

We thank professor Edson and the Linguistic Support Department at Unichristus for help in translating the text.

\section{References}

1. World Health Organization. Global tuberculosis report 2013. http://apps.who.int/iris/bitstream/10665/91355/1/9 789241564656_eng.pdf (Accessed on November 18, 2013)

2. Bruguera M, Rodes J, Vilardell E, Gibert-Queralto J. [Portal hypertension associated with autonomous hepatic tuberculosis]. Rev Int Hepatol. 1968;18(7):895-903.

3. Gibson JA. Granulomatous liver disease and portal hypertension. Proc R Soc Med. 1973;66(6):502-503.

4. Gaya DR, Thorburn D, Oien KA, Morris AJ, Stanley AJ. Hepatic granulomas: a 10 year single centre experience. J Clin Pathol. 2003;56(11):850-853.

5. McCluggage WG, Sloan JM. Hepatic granulomas in Northern Ireland: a thirteen year review. Histopathology. 1994;25(3):219-228

6. Drebber U, Kasper HU, Ratering J, Wedemeyer I, Schirmacher P, Dienes HP, Odenthal M. Hepatic granulomas: histological and molecular pathological approach to differential diagnosis--a study of 442 cases. Liver Int. 2008;28(6):828-834.

7. Maddrey WC. Granulomas of the liver. In: Schiff's Diseases of the Liver, Eighth Edition, Schiff ER, Sorrell MF, Maddrey WC (Eds), Lippincott-Raven, Philadelphia. $1989 ; 1572$. 